\title{
New teaching methods in use at UC Irvine's optical engineering and instrument design programs
}

Donn Silberman, T. Scott Rowe, Joshua Jo, David Dimas

Donn M. Silberman, T. Scott Rowe, Joshua Jo, David Dimas, "New teaching methods in use at UC Irvine's optical engineering and instrument design programs," Proc. SPIE 8481, Optics Education and Outreach II, 848103 (15 October 2012); doi: 10.1117/12.928814

EDIE Event: SPIE Optical Engineering + Applications, 2012, San Diego, California, United States 


\title{
New teaching methods in use at UC Irvine Optical Engineering \& Instrument Design Programs
}

\author{
Donn M. Silberman ${ }^{\mathrm{a}, \mathrm{d}}$, T. Scott Rowe ${ }^{\mathrm{b}, \mathrm{d}}$, Joshua S. Jo ${ }^{\mathrm{c}, \mathrm{d}}$, David Dimas ${ }^{\mathrm{d}}$ \\ ${ }^{a}$ PI (Physik Instrumente) L.P., 5420 Trabuco Rd. Ste., Irvine, CA 92620, ${ }^{b}$ Rowe Technical Design, \\ 24865 Danafir, Dana Point, CA 92629, 'Syprosoft Engineering, 1150 Main St \# E. Irvine, CA \\ 92614, ${ }^{\mathrm{d}} \mathrm{UC}$ Irvine Extension, Pereira Drive West of East Peltason Dr., Building 234, Irvine, \\ California 92697
}

\begin{abstract}
New teaching methods reach geographically dispersed students with advances in Distance Education. Capabilities include a new "Hybrid" teaching method with an instructor in a classroom and a live WebEx simulcast for remote students. Our Distance Education Geometric and Physical Optics courses include Hands-On Optics experiments. Low cost laboratory kits have been developed and YouTube type video recordings of the instructor using these tools guide the students through their labs. A weekly "Office Hour" has been developed using WebEx and a Live Webcam the instructor uses to display his live writings from his notebook for answering students' questions.
\end{abstract}

Keywords: Optics education, lens design, optical system design, optomechanical design, optical instrument design, optical engineering education, hands-on optics, hybrid teaching methods, on-line optics labs.

\section{INTRODUCTION}

Two years ago we reported on this new program $^{1}$ of optical engineering and instrument design at the University of California Irvine Extension. At that time we had transitioned from an earlier program at Irvine Valley College's Advanced Technology and Education Park. Here we will describe the motivation for the new teaching methods now in use in these programs and we will discuss them in some detail. We will also provide an update on the programs since 2010 , mention some of the recent successes and chart the path for future development.

\section{UPDATE FROM 2010}

Before beginning the update from 2010, we mention that in the previous report ${ }^{1}$, we provided a program overview that centered on a Venn diagram, a program curriculum including required and elective courses and the then current course offerings. Here we will refer the reader back to that paper for those details and the program website for current offerings and programmatic details. One on-line tool we use as a method to introduce potential students to our programs is the Webinar. This can be seen on the homepage of the program website and has been very helpful in allowing individuals to learn how our programs and courses can help them with their educational goals and objectives and learn about new teaching methods we are using.

The main updates from 2010 center around the new instructors we have hired and the new teaching methods we are using. This has come about in a large part because of the extensive support from the UC Irvine Extension staff and most importantly their Instructional Technology staff and Distance Learning Center (DLC). Other updates include the changes in demographics of our students and the fact that we now have a number of students who have taken and passed enough courses to receive

Optics Education and Outreach II, edited by G. Groot Gregory, Proc. of SPIE Vol. 8481

$848103 \cdot$ ? 2012 SPIE · CCC code: 0277-786/12/\$18 · doi: 10.1117/12.928814 
their Certificate in either our Optical Engineering program or our Optical Instrument Design program.

The new instructors include Scott Rowe, Joshua Jo, Donn Silberman, Charles Vice and beginning in September 2012, Keith Kasunic. Scott has taught our Optical Instrument Design course, Joshua is teaching our Introductory and Advanced Lens Design courses, Donn is teaching our Geometric and Physical Optics courses, Charles and Scott are teaching Optomechanical Component Design and Keith will be teaching a new course titled, 'Optomechanical Systems Engineering.' We are also in the process of hiring new instructors for other current and future courses and will mention that in the last section of this paper.

We had students receive their certificates in Optical Engineering (8) and Optical Instrument Design (2) in June 2012 and more will be receiving them on an ongoing basis each quarter; as they apply for candidacy and complete their requirements.

\section{NEW HYBRID TEACHING METHODS}

In this section we will first discuss the motivations for these new methods. The primary motivation is to reach more students in geographically dispersed areas. Other important motivations include having the lectures and live student/instructor interactions recorded for student review after each class period or office hour is over. This has proven to be very helpful to students, as this material tends to be very technical and detailed and students may miss key points during the lectures.

Reaching geographically dispersed students, was necessitated due to the large geographic area covered by Southern California and the traffic congestion preventing potential students from enrolling. Even though we did and continue to have students who drive up to 1 hour each way to attend courses at the UC Irvine campuses; we still viewed this as a major challenge.

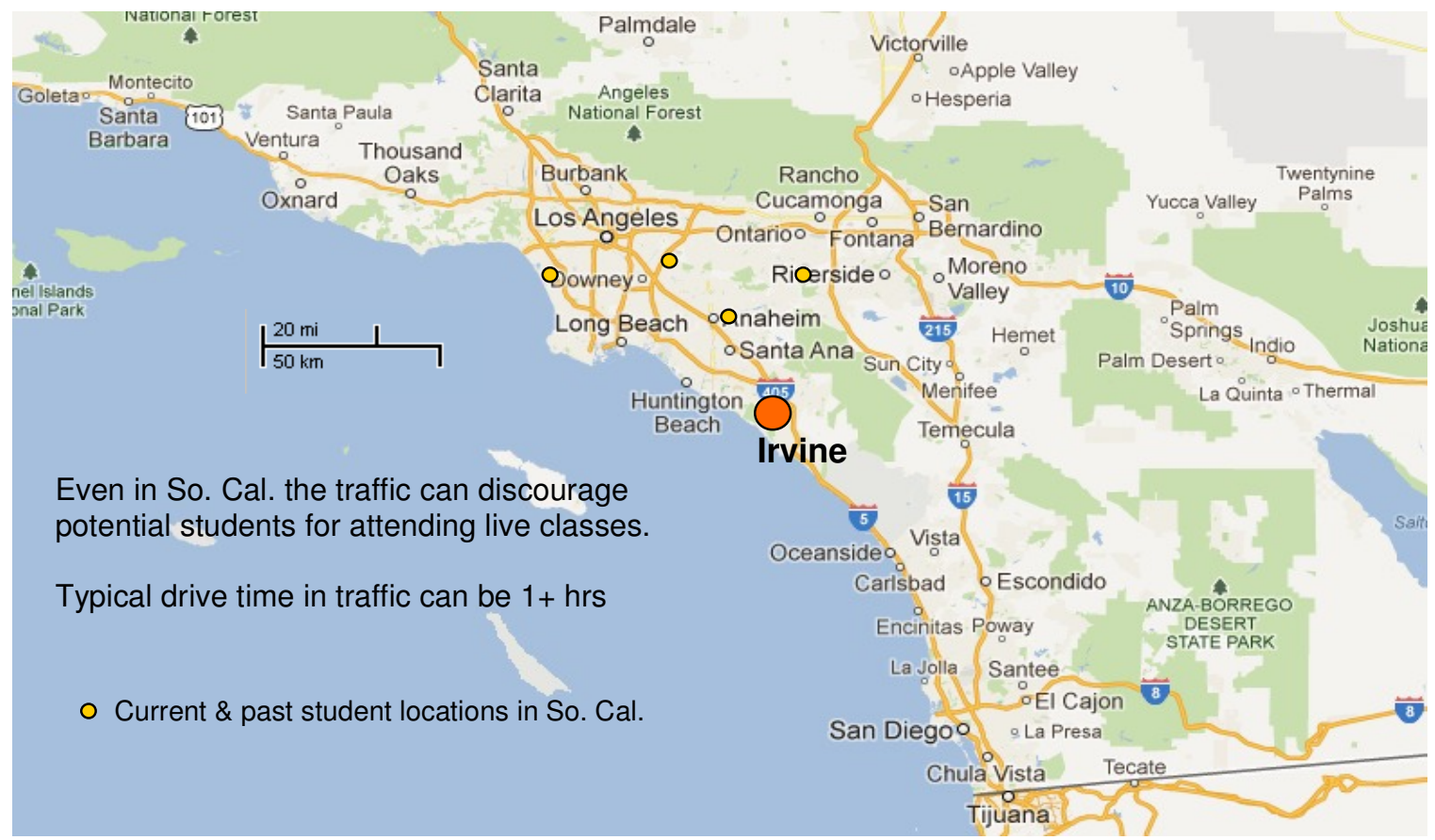

Fig. 1. Southern California demographic for students in UC Irvine Optical Engineering programs. 
After our first year of courses, we approached the UC Irvine Extension Instructional Technology and Distance Learning Center staff and asked if we could try a new Hybrid Teaching method. UC Irvine Extension had an extensive On-Line Distance Education capability, but had never offered a course where the instructor was in the classroom with some students, while other students were live on-line via WebEx. The main question we had to answer was: Why record the live lectures? The answers we found were:

- Instructors move through complex course material quickly and sometimes it is challenging for students to keep up.

- Students ask questions / instructors to provide answers, and sometimes this goes too quick for adequate note taking

- Being able to review the lectures improves the students' ability to comprehend and retain the course material.

- Allows instructors to focus time on direct interaction with students (where a majority of the learning takes place)

- Gives students the ability to stop and replay sections of the lectures and office hour interactions as needed

Then the next question was: How many more students could we reach using these new methods?

The answer is provided in Figure 2 below, where we see a recent map of students enrolled, including students near Toronto, Boston, Seattle and in Israel. Our Introduction to Lens Design course last fall had about 10 students from outside Southern California. We believe these new teaching methods will continue to attract students from many more diverse locations from around the world.

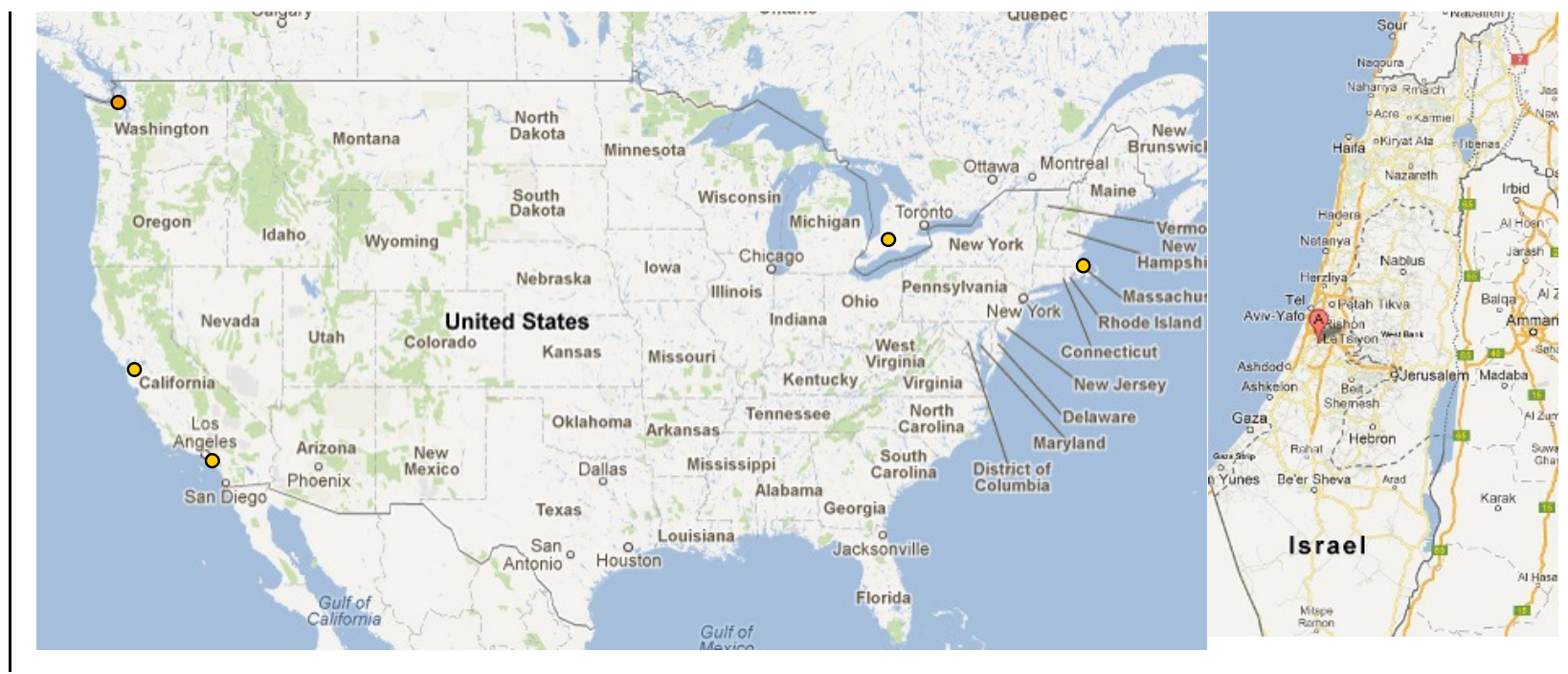

Fig. 2. Current demographic for students in UC Irvine Optical Engineering \& Instrument Design programs.

\section{NEW HYBRID TEACHING TOOLS}

The new hybrid teaching tools includes UC Irvine Extension WebEx Service, Webcams, Extensive IT support from UC Irvine Extension's Instructional Technology and Distance Learning Center staff along with Network licenses for optical and mechanical software tools. 
An example of retrieving recorded lectures from the UC Irvine Extension WebEx Service is shown in Figure 3 below.

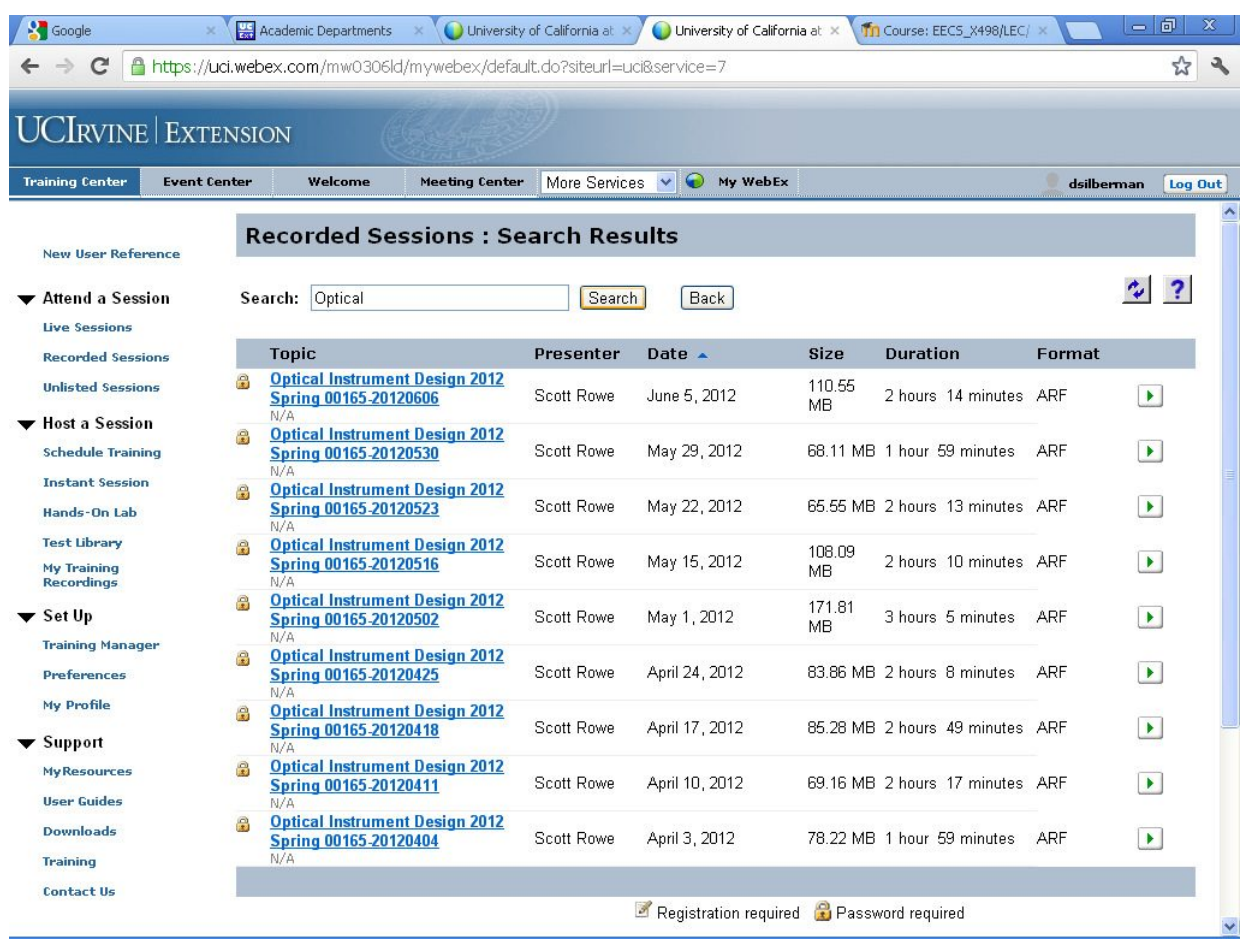

Fig. 3. Typical screen shot for students to review recorded live lectures.

This screen shot shows how a student can retrieve and review a recorded lecture from throughout the course. This can assist the students in recalling information delivered during the course lectures and includes the slides the instructor was showing, his/her audio discussion and any other information, like student questions and instructor answers that were recorded during the live lecture.

In addition, Webcams video and audio that were used for various purposes were also recorded and we will discuss this in more detail in a later section in this paper.

One of the main reasons for our successes with these programs and the new teaching methods has been the outstanding support from the UC Irvine Extension Instructional Technology and Distance Learning Center staff. In addition to the technology they offer students and instructors, they offer extensive training programs for instructors and complete on-line support for both students and instructors. They also have well trained staff available live on the phone and through live chat lines at the Student Services and the IT Departments. Typically, an IT staff member will be on-line at the beginning of each session to make sure all is well; then they sign off.

The screen shot in Figure 4 shows the home web page for the UC Irvine Extension Instructional Technology services. Here we see that they have a particular Computer Lab Location which is an excellent resource we used during our first experiments with the Hybrid Teaching Tools. Each student who came to the classroom for any of our Optical Engineering required core courses had a PC to use on the desk and they could also use their personal laptop through the UC Irvine WiFi system. This enabled the students in the classroom to act as eyes and ears to assist the remote students and the instructor make sure the remote students could interact with the instructor and the 
other students. This was a very important development in breaking the barriers and helped us begin to use all the advanced information technology tools the school has to offer.

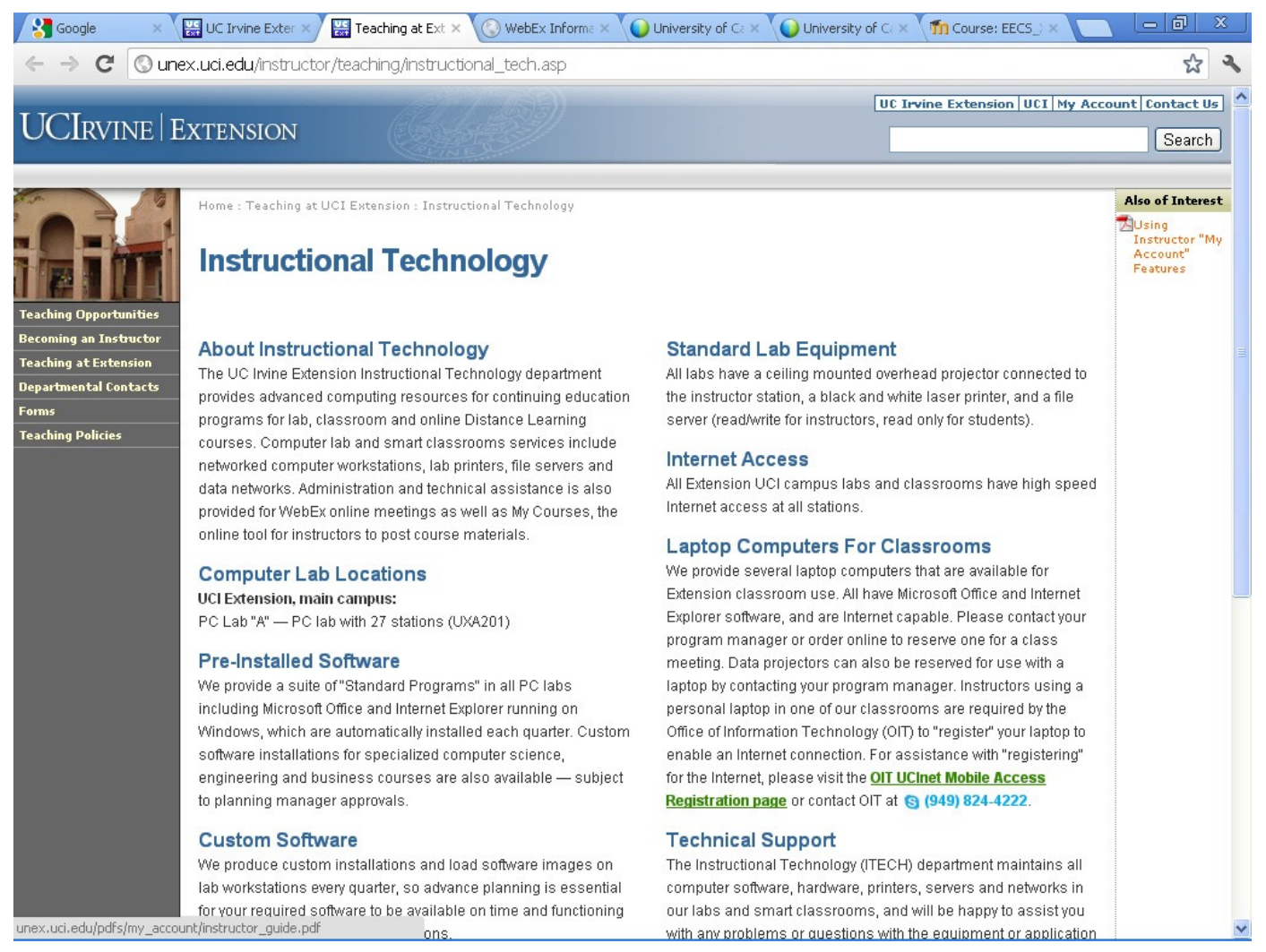

Fig. 4. Screen shot from UC Irvine Extension Instructional Technology home web page.

Regarding working with network licenses from optical and mechanical software vendors, we began using Zemax Lens Design Software tools and have had an excellent ongoing working relationship with their customer support team. Combining this to the UC Irvine Extension IT department staff, the students and instructors have had a pretty much trouble free experience (we did have a learning curve in the first year, but we are now over that). We have also used SolidWorks Students Edition and have not had trouble with that, although we have had much less experience to date with this portion of our program. Recently, we have introduced our Geometric and Physical Optics students to OSLO and CODE V and will be having our students use these and other software tools going forward. We will touch on this again in the final section of this paper.

\section{NEW ON-LINE TEACHING METHODS}

New on-line teaching methods are and have been used in our Introduction and Advanced Lens Design courses and our Physical and Geometric Optics courses. These methods are also scheduled to be used in our new Optomechanical Systems Engineering course and will be used in other courses as well.

Our Geometric and Physical Optics courses are delivered through using the following methods: 
- A main home web page exists for each course and is divided into weekly sections.

- Recorded Lectures are available in both Flash \& SmartPhone versions

- Supplemental On-Line materials are provided and include:

- Links to other websites

- Java applets

- Significant papers in pdf file formate

- Hands-On Lab Assignments

- Weekly WebEx Office / Lab Hour

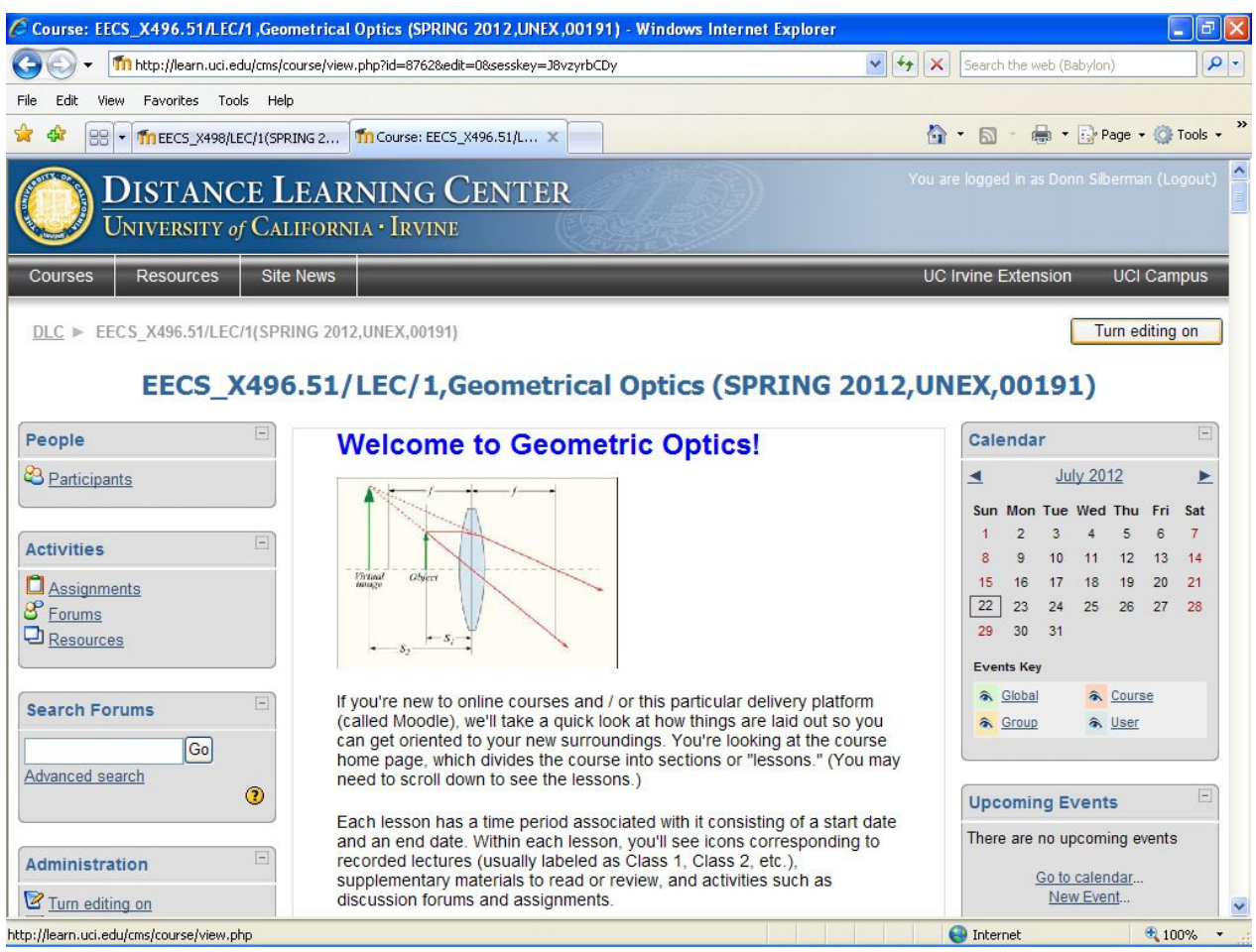

Fig. 5. Screen shot from Geometric Optics Home Web Page. 
The screen shot shown in Figure 5 of the home web page for the Geometric Optics course shows just the beginning of what the students and instructors see when they log into their On-Line course. The Moodle Learning Management Systems or LMS provides a strong framework for learning for the students and valuable and easy-to-use set of tools for course design and delivery for the instructor. Tools within Moodle allow the instructor to design the course using a variety of student activities, assignments and resources as mentioned above for the Geometric and Physical Optic courses and discussed below for the Introductory and Advanced Lens design courses. Each of these activities or resources has an easily recognizable icon so students quickly recognize what they are being asked to do during each week of the course (see fig 7 below). Other features of the LMS system is its ability to automatically grade multiple choice quizzes and accept (via a simple website upload) and track assignments submitted by students. The system makes it easy for instructors to grade assignment and quizzes and provide student feedback immediately. Readers who are interested in learning more details about this "Moodle Shell" should contact the authors for a guest pass to one of our courses.

Recorded lectures are available for students to view either on their personal computers (PCs) or on their SmartPhones. This provides the students the capability of reviewing their lectures while they may be commuting or waiting around while traveling (airports, buses and trains.) In Figure 7 examples of the links to the Flash and SmartPhone recordings are shown. Also is an example of the Hands-On Lab work assignment, some supplemental pdf files and the link to upload the weekly homework and labwork assignments

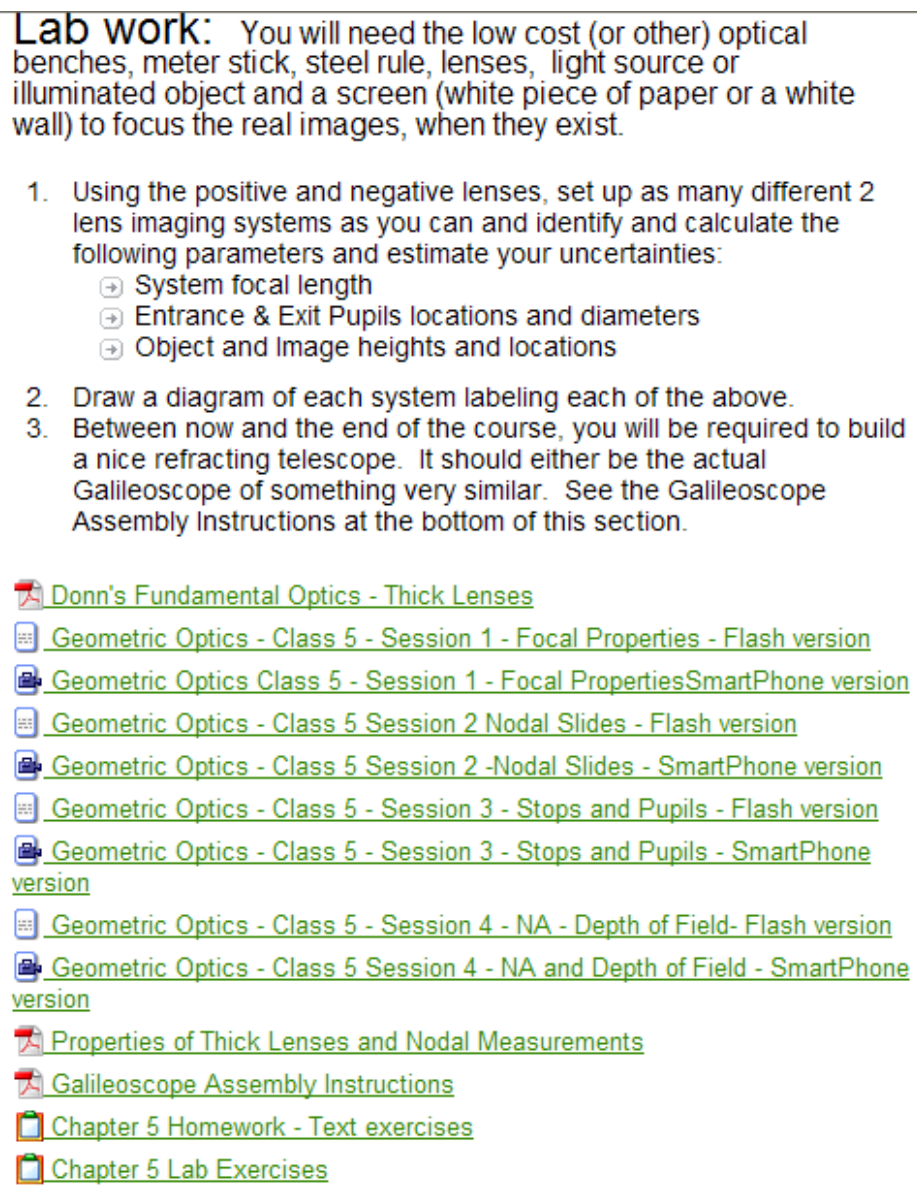

Fig. 7. Screen shot from typical weekly section of main web page. 
A special web page was set up on the web site of the Optical Society of Southern California (with links from the official UC Irvine Extension on-line registration web page for this course) that details the Hands-On Lab equipment that is required for this Geometric Optics course. This was done to allow the instructor flexibility since he did not have access to the registration web page.

Home $\circ$ UC Irvine Geo Optics Lab Kits

The components for the UC Irvine Geometrics Optics Lab Course can be purchased as follows:
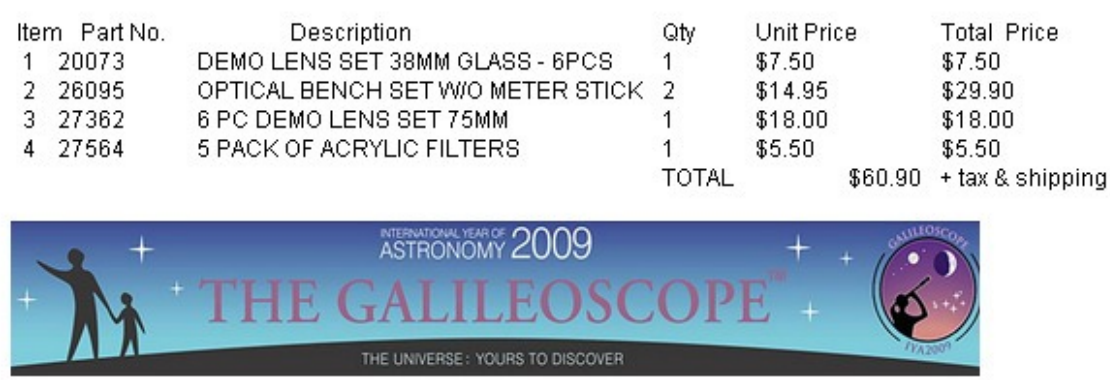

http://mww. Scientificsonline.com/galileoscope-kit.html $\$ 49.95+$ tax \& Shipping

https://mwnum galileoscope.org/gs/

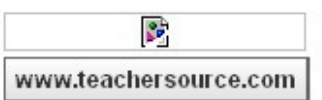

$\begin{array}{clllll}\text { Item } & \text { Part No. } & \text { Description } & \text { Qty } & \text { Unit Price } & \text { Total Price } \\ 1 & \text { MIR-135 } & \text { Mirascope } & 1 & \$ 7.95 & \$ 7.95 \\ 2 & \text { SM-3 } & \left.\text { Plastic Kaleidoscope Mirror (1.625" } \times 9^{\prime \prime}\right) & 3 & \$ 1.95 & \$ 5.85 \\ 3 & \text { PSM-100 } & \text { Equilateral Prism - 25 } 75 \text { mm (Glass) } & 1 & \$ 6.95 & \$ 6.95 \\ & & & & \text { TOTAL } & \$ 20.75+\text { tax \& shipping }\end{array}$

Fig. 8. Screen shot from OSSC web page with lab equipment requirements.

An example of a page of a student's lab work report is shown in Figure 9. Here, an experimental set up is shown where the student has a two (2) lens system set up on a low cost optics bench made up of a wood meter stick and metal lens and screen holders. The USAF target (object) is illuminate from behind and the image is evaluated on the screen. The numerical parameters are also shown on this page by the student. 
System 1

To find stop we image all apertures into object space

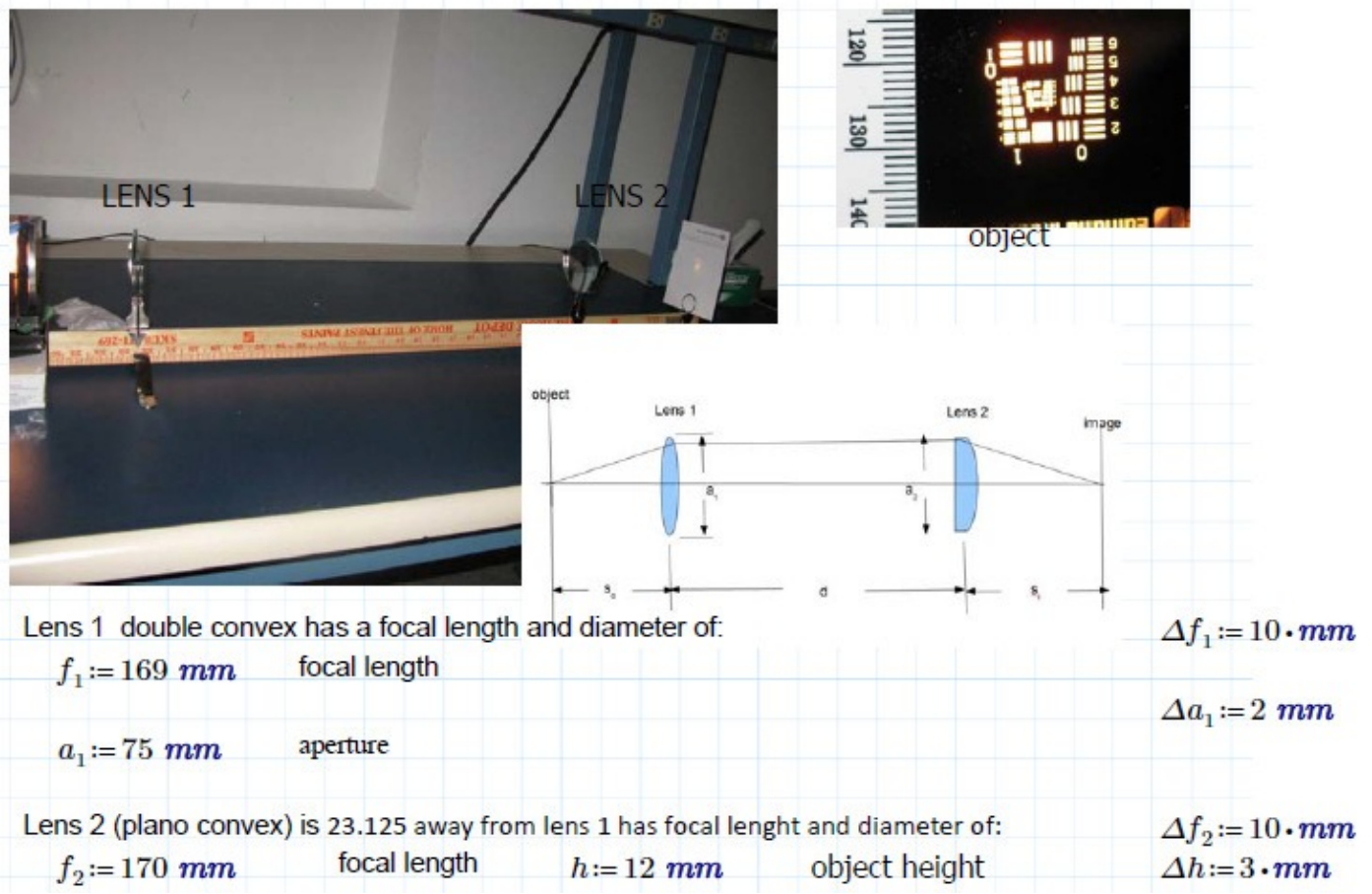

Fig. 9. Screen shot from student's lab work report. Geometric Optics Course.

A main point of this paper is to demonstrate the success of including this Hands-On Lab requirement in an On-Line Distance Education course in Geometric Optics. Similar required experiments were developed and implemented for the Physical Optics course using low cost diffraction gratings, polarizers, light sources and detectors.

As mentioned earlier, weekly live WebEx Office Hours are used to provide student / instructor interactions and those are also recorded for later review by the students as needed. Typically, each week includes $\sim 1.5-2$ hours of recorded lectures and $1-1.5$ hours of live WebEx Office Hours. An example of a student viewing of a recorded WebEx Office hour is shown in Figure 10. The instructor has the slide stack up on the screen as the students ask questions about the lecture. All of the students can interact live on-line in this format, with each other and the instructor. Many times, the instructor allows the students to answer each others' questions in an on-line seminar format. 


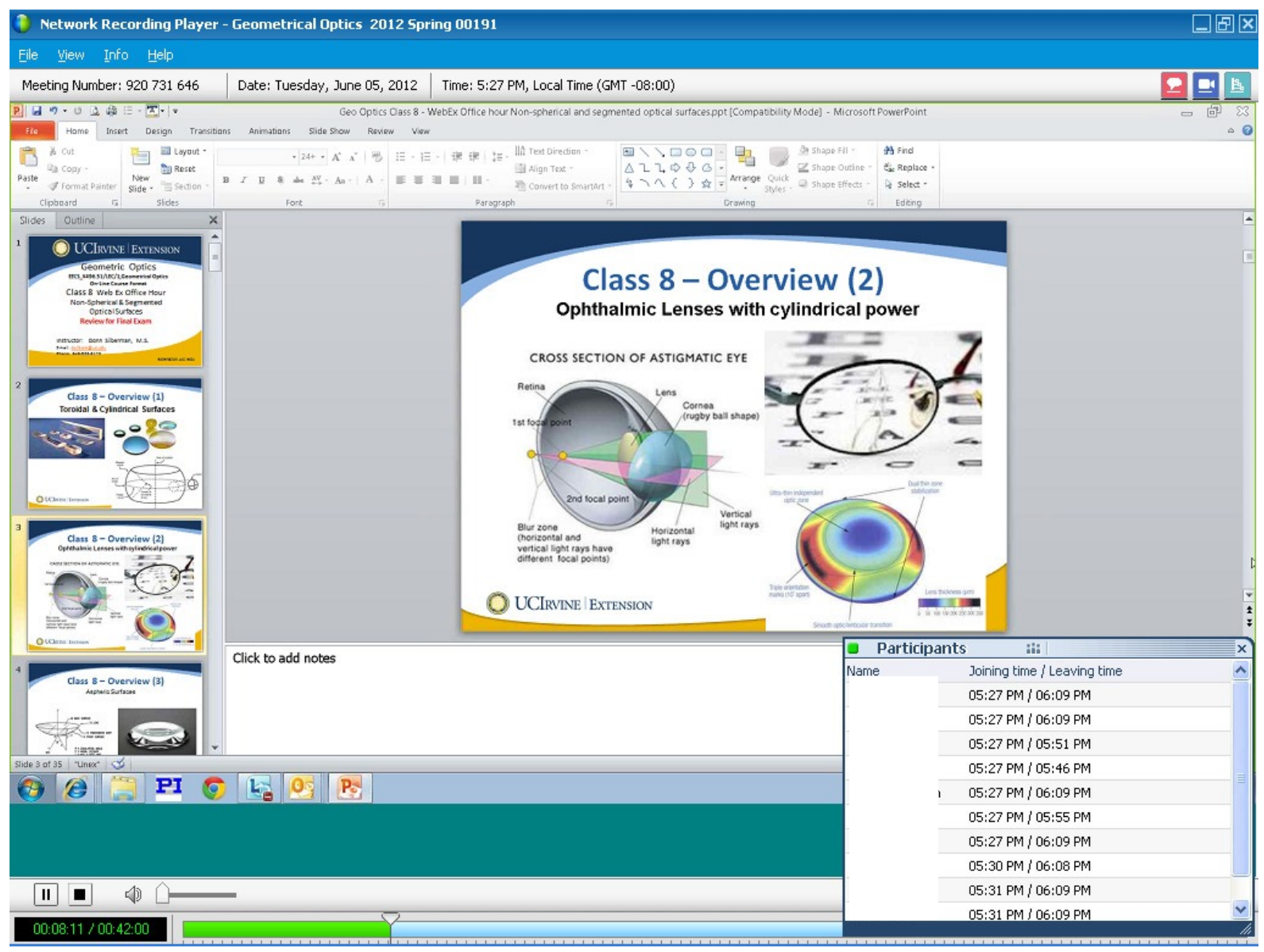

Fig. 10. Screen shot from recorded On-Line WebEx Office Hour. Geometric Optics Course.

Several different on-line teaching methods were developed and implemented for the Introduction and Advanced Lens Design courses. They included:

- Recorded Lectures including the use of a WebCam

- Weekly discussion forums with required (and graded) participation

- Supplemental On-Line materials

- Links to other websites

- Java applets

- Industry Standard Software tools

- Weekly WebEx Office / Lab Hour including the use of the WebCam

- Quizzes and Exams (some with automated grading for immediate feedback) 
Using industry standard optical design software to demonstrate lens design concepts and theory discussed in an earlier section of the recorded lecture, the instructor uses the WebCam to draw by hand the concept of the lens system, in this case how to design from a simple plane parallel plate (PPP) to the complicated triplet in a minute with the industrial standard optical design software.

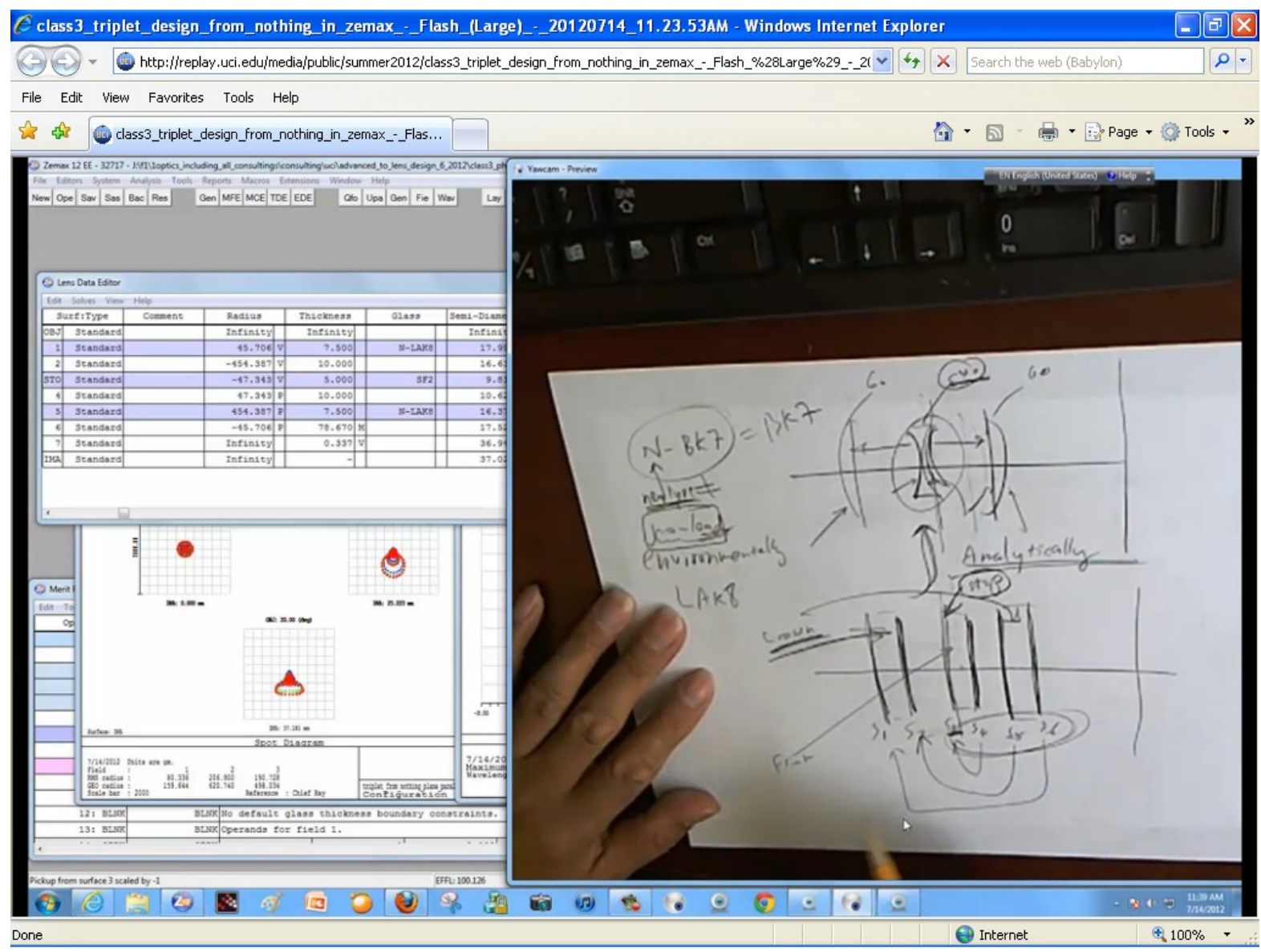

Fig. 11. Screen shot from recorded lecture from the Advanced Lens Design course showing the concept of the Triplet design with the industry standard optical design software and the use of the WebCam. 


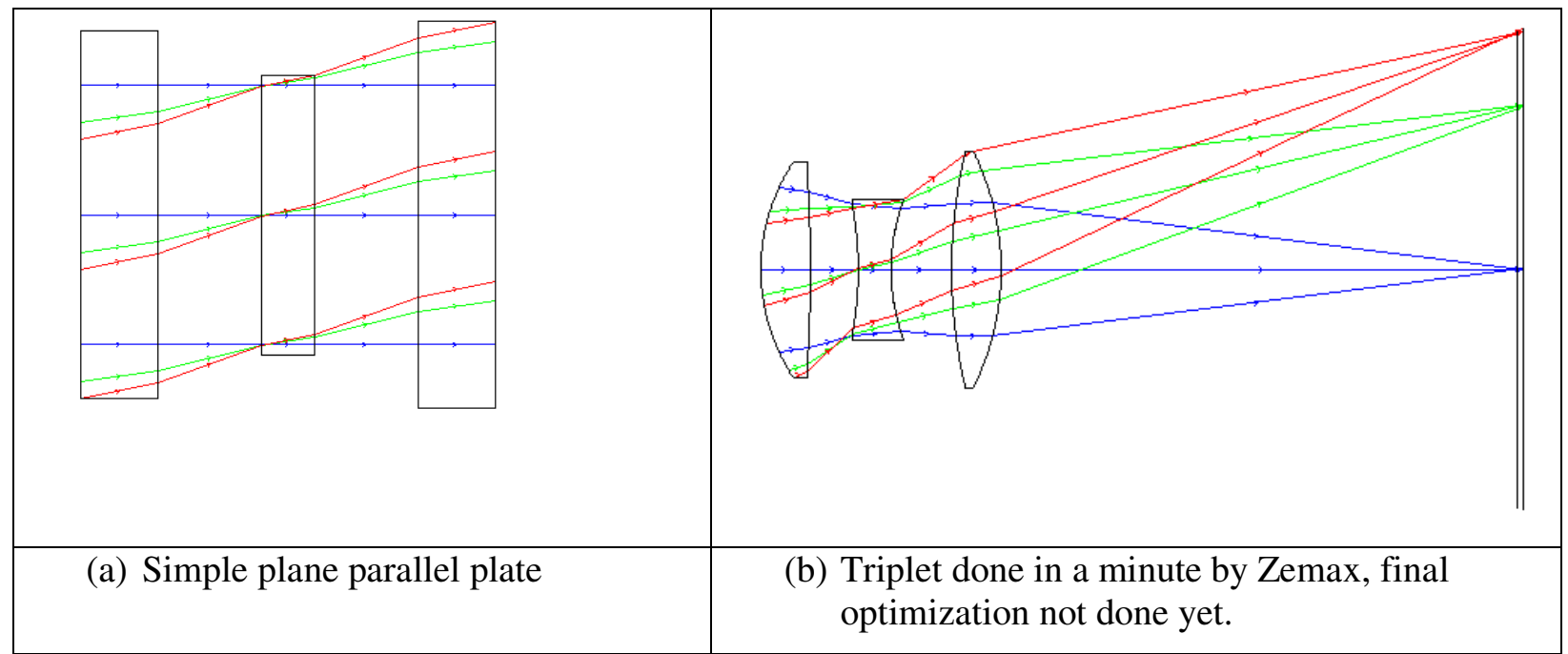

Fig. 12. Showing the triplet design can be done by one click with appropriate use of the default merit function of optical design software with the conceptual explanations (a) plane parallel plate (PPP) (b) triplet done in a minute.

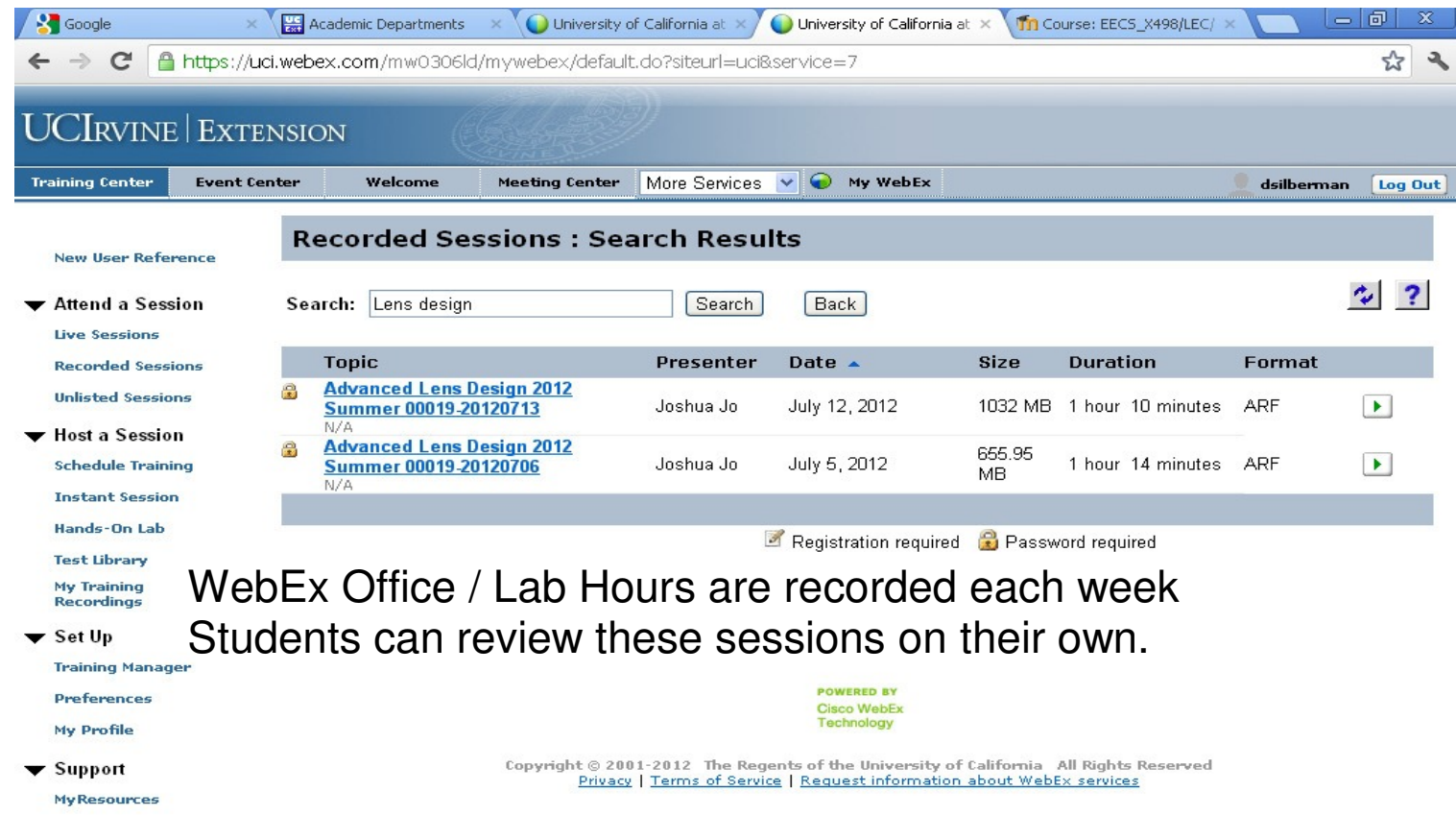

Fig. 13. Screen shot from UC Irvine Extension WebEx recorded sessions from the Advanced Lens Design course showing recorded WebEx Office Hour sessions that the students can review. 


\section{FUTURE DEVELOPMENTS}

Since these programs began in 2009, we have made many advances in the teaching methods used. As of this report we are working on:

- Adding more new instructors including two who have been involved professional optical engineering training for many years.

- Continuing to offer more courses, including:

- Introduction to Lasers

- Introduction to Fiber Optics

- Optical Metrology \& Interferometry

- Precision Positioning \& Motion Control for Optical Systems

- Introduction to Vibration Control

- Bringing on the ground temporary lab equipment for specific courses to the UC Irvine Extension Campus

- Adding on the ground lab facilities in cooperation with Irvine Valley College ATEP campus and local optics businesses.

We also have an outline for a 1 week summer course at the UC Irvine Extension Campus that would introduce potential students to these courses and the programs.

We are grateful to our students, our instructors, the UC Irvine Extension Staff and our Advisory Committee who all continue to support these programs.

\section{REFERENCES}

[1] Silberman, D., Doushkina, V., "New optical engineering and instrument design programs at the University of California, Irvine Extension", in Optics Education and Outreach, G. Groot Gregory, Editors, Proceedings of SPIE Vol. 7783 (SPIE, Bellingham, WA 2010), 77830N. 